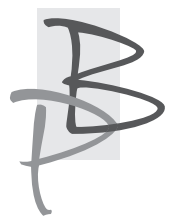

Bridget Sheridan*

University of Toulouse 2, Jean Jaurès, France

https://orcid.org/0000-0002-6967-6434

\title{
Mapping the Way: The Use of Maps in Artistic Projects, Working with Migrants and Refugees
}

Abstract: This article deals with three art projects which take into account the relationship between maps, migration and memory. We shall analyse how Céline Boyer, Bouchra Khalili and Marie Moreau artistically respond to the diverse waves of migration in Europe. In each of their respective projects, engagement with these themes and with individual participants created opportunities for the transmission of knowledge and experience. The connection between maps and power is explored relative to these artistic projects and related processes. Whether it be photography, writing, video installation or participative ateliers, all three artists seem to pinpoint the importance of the hand when it comes to telling and mapping a story.

Key words: art walking, mapping, migration, hand, Boyer, Moreau, Khalili.

\footnotetext{
Bridget Sheridan is a lecturer in visual arts at the University of Toulouse, where she teaches theory of art and contemporary art practices. She completed her PhD in 2016 at Toulouse University, France. Art walking and the body in motion are at the heart of her research, which incites us to explore collective memory via walking in the landscape, photography and video practice. As an artist, she has exhibited her work across France and England. In 2013 she received an award at the Nîmes Contemporary Art Biennale.
} 


\section{Introduction}

Artists have been using maps since time immemorial. Whether it be illustrating maps, using them in installation work or imagining new systems of projection, the map is a never-ending source of inspiration for the artist. Maps can be explored, enabling one to dream, to imagine, leading one through places one used to live in or on routes one had once travelled, guiding one through places one has settled in or helping one plan journeys to come. Hence, we can grasp how some artists who work with migrants use maps in their art projects. Maps' plasticity becomes evident and we can perceive them as matter to explore and to manipulate.

Céline Boyer, Bouchra Khalili, and Marie Moreau have all used maps while working on art projects with migrants. In each piece of artwork, the hand seems to be of great importance, just as much as maps. Thus, we shall ask ourselves how the hand and the map interact in Bouchra, Khalili and Moreau's work. How does a map become cathartic for displaced people? And how does the artist use this powerful system of representation to evoke memory and help migrants to adapt.

This paper will explore the works of Boyer, Khalili, and Moreau relative to the above questions. Boyer, Khalili and Moreau's artistic approach to maps and migration differ in several ways as we shall see as the article unfolds. However, the three works are complementary here in that each piece of art responds to another. The artists' works were analysed through an almost Warburgian approach in that my research in visual arts acknowledges both contemporary art and historical works of art, connecting established and more innovative theories. In this paper, following the offbeat path enables the reader to interpret works of art in a unique way, bringing to light the three pieces of art, the singularity of each creative form and how memory, maps and migration all three converge in different ways.

First, we shall look at Céline Boyer's work, at her series of hands, Empreintes, meaning 'imprints'. Here we shall focus on the metaphor of the skin as territory. Then, we shall centre on Khalili's Mapping Journey Project. Unlike Boyer's static, photographic hands, Khalili's move in his series of videos leads us to focus on the gesture and language of the hand. Furthermore, we are able to then distinguish between the cartographic map and the sketch map. Tim Ingold's definition of "cartographic map" and "sketch map" will be defined and 
further discussed. Finally, Moreau's work happens to be more participative, in that the migrants work on blank paper or even on material, weaving their story into the fabric, the gesture of the hand becoming part of the map. What counts here seems to be the lines, which are those of the wayfarer.

\section{Each hand tells a story}

Céline Boyer is a French photographer. She began a series of photographs in 2009 entitled Empreintes, meaning 'Imprints', an ongoing series in progress, for she collects more and more stories and photographs of hands as she goes along through life. In terms of migration, adaptation, and memory, this work further explores where we come from, how one's body adapts and remembers, and one way that our stories and experiences can be told through our bodies

It all began when she was a young girl. She used to play a game with her globe, her eyes shut, and point her index finger somewhere. She would then do some research on whatever mysterious place she had located and try to imagine another world and all the possibilities of another life elsewhere. She had discovered the power of cartography and how systems of projection can evoke distant places and time.

Boyer then decided to put on her great grandmother's wedding ring and photograph her own hand, superimposing the picture with the map of the Ural Mountains, her great grandparents having emigrated from Russia. Although she found the image curious, she was, however, troubled by the result of this superimposition. Hence, she began to explore the past, asking her grandfather to have his hand photographed in turn. The suggestive strength of this work led Boyer to photograph other hands, those of friends, of friend's friends, and then, friend's acquaintances whom she did not know. This is how her art project, Empreintes, was born.

The photograph being the medium of communication, she asks each person to present himself or herself, showing the palm of their hand. The photographer and each person have to trust one another. While Boyer photographs their hands, they tell their story and confide in her, sharing the secrets of their past. Boyer superimposes a cartographic map of the territory from where the person comes onto the photograph of the hand. The exhibition juxtaposes each image with a text, a testimony, a story of the person attached to their place of 
birth, to his or her memory, thus creating a collective memory made of maps, hands and stories. This goes to show how rich the regions and towns of France are, in that people have immigrated into France over time, from all different parts of Europe and even from all over the world.

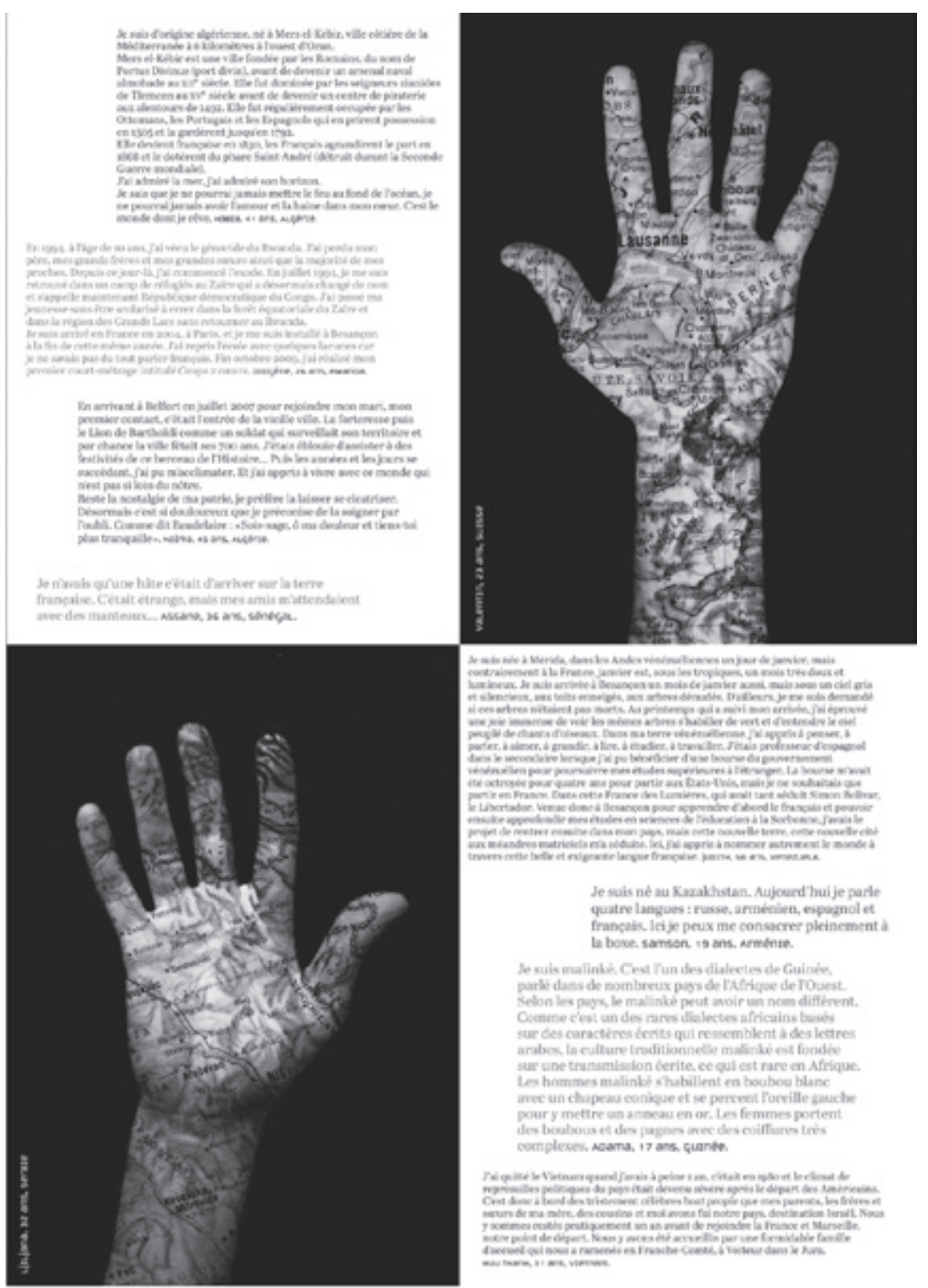

IMAGE 1. Céline Boyer, Empreintes, image taken from the book documenting the photographic and text work, Paris, Broché, 2013. 
The hands form a series of portraits, in that each image evokes the path of life each person has travelled along. The cartographic signs, the rivers, roads and mountains, the names of towns, villages or hamlets travel across the skin, just like lines on the palm of the hand, those a palmist would study in chiromancy. Boyer's hands create a metaphorical story of the skin as territory, where rivers and roads are woven into the wrinkles and veins of the hand and where mountains and valleys meet the curves of fingers, palms and wrists. The colourings of the cartographic map shadow and highlight the skin of the hands, bringing them to life and suggesting a "unique landscape", using the words of David Le Breton, a French anthropologist.

Henri Focillon used these same words in 1943, in a short essay on hands. He asked himself how the hands, being a mute organ of the body, are so capable of moving us. He saw the palm of the hand as a receptacle or even a repository of forgotten memories. The skin of the palm resembles a "unique landscape, with mountains, a great central depression, narrow fluvial valleys, [...]"2.

Boyer's hands speak to us in their own language. Our eye travels along the lines of the hands where the plasticity of the map meets that of the skin in order to conjure up images of distant lands and memories.

\section{Retracing the journey}

Gilles A. Tiberghien perceives the map as a "dream machine"3. The map is a system of representation, which is actually drawn by the human hand. The fingers proceed, transcribing lines and levels, sketching, scribbling and scrawling, while the genius of the cartographer translates the rhythm and the melody of the territory. At that instant, the map becomes a space one can explore. The artist opens up this cartographical space and brings it to life. More precisely, it is the hands that bring it to life, for we manipulate maps, we point at different spots and locations, and we follow lines with a finger. These gestures result from either real or mental journeys, from the movements of the mind and the

1 D. Le Breton, La peau et les traces, Sur les blessures de soi, Paris: Editions Métailié, 2003, p 24.

2 H. Focillon, Éloge des mains, [in] La vie des formes, Paris 1943, p. 103.

3 G. A. Tiberghien, Finis Terrae: Imaginaires et imaginations cartographiques, Paris: Bayard, 2007, p. 169. 
body. Moving across a map is quite similar to moving through space. Thus, a map could help us recall a walk, a trip or a journey.

Bouchra Khalili's Mapping Journey Project could be thought of in this way. Over a period of four years, Khalili travelled round the Mediterranean Basin collecting testimonies of migrants; we could envisage this proceeding as an unusual form of interview. The migrants confide in Khalili while their hands travel along the map in a video installation. Each video tells the story of a migrant Khalili encountered. The sensual movement of the hand in these videos pinpoints how our hands constantly interact with our voice, sound and gesture complementing one another. As Henri Focillon says, hand gesture articulates our everyday life. It confers rhythm and colour to one's existence, voice and hands working together, exchanging signs and sound. The hands create depth in Khalili's work as they move along the maps, defining space and bringing the fixed and rigid cartographic maps to life, creating what Ingold calls a sketch map, one that accompanies the voice. Ingolds "sketch map" shows the way people inhabit the world ${ }^{4}$. The ephemeral movement of the body and gesture accompany stories and the path of the "wayfarer" travelling through life:

The lines on the sketch map are formed through the gestural re-enactment of the journeys actually made, to and from places that are already known for their histories of previous comings and goings. The joins, splits and intersections of these lines indicate which paths to follow, and which can lead you astray, depending on where you want to go. They are lines of movement. In effect, the 'walk' of the line retraces your own 'walk' through the terrain'. 




IMAGE 2. Bouchra Khalili, The Mapping Journey Project, installation view, 8 videos, sound, 2008-11.

Florence Jou underlines how the map in Khalili's video-installation resembles the "sketch map" 5 . The gesture transforms the normative surface of the map, revealing depth as one traces trajectories bringing it to life. The lines drawn by the migrants resemble those one performs while walking, in that the trajectories each individual follows involve both the body and the mind. The ephemeral lines appear on the map as Khalili's storytellers remember where they came from, the places they travelled through, the path they followed and where they settled down, whether temporally or permanently. The trajectories of the migrants make their way to the surface of the map as Khalili's migrant's hands retrace their trajectories. In this way, they remember how their whole body and mind are connected to the territory.

5 F. Jou, The Mapping Journey Project: la cartographie à l'état dynamique, [in] Textimage, online article, http://www.revue-textimage.com/12_varia_5/jou1.html [Accessed: 18 August 2017] 


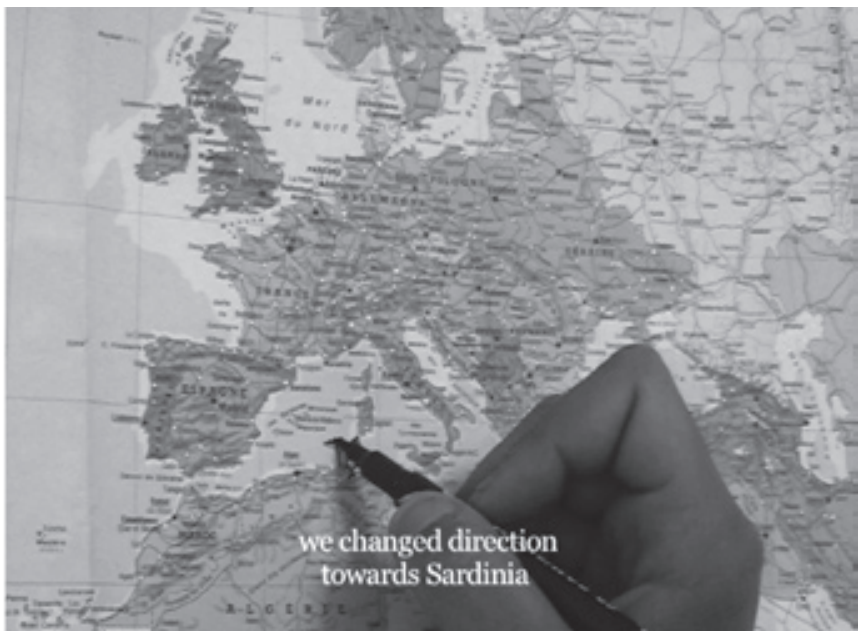

IMAGE 3. Bouchra Khalili, The Mapping Journey Project (detail), 8 videos, sound, 2008-11.

\section{Participative ateliers}

We can say that Khalili's work is participatory in a certain sense. However, French artist Marie Moreau took participation a step further when she agreed to join a research project in 2013, along with twelve asylum seekers, two researchers in geography and three other artists. This creative research project involved contemporary migratory experiences. The artists, researchers and migrants worked together creating maps. Their goal was to re-invent the system and signs of the map, which debase the border to a line for instance, or migration to an arrow. They endeavoured to translate the political and practical complexity of the journey. The artistic and scientific experiment of this project raises several questions. For example, during these experimental ateliers, how is it that the gesture of the hand, combined with mapping techniques, can help migrants to adapt?

Marie Moreau decided to use her own sister's experience as a starting point for the project. Her sister, a social worker in a home in Grenoble, would regularly point out how the paper table cloths would become a surface for ephemeral and personal trajectories, facilitating cooperation, aid and, by all means, communication between the residents of the home, simplifying conversation when individuals did not necessarily speak the same language. Thus, maps would become a calling card. Strictly speaking, mapping would mean intro- 
ducing oneself. There would be no words, or hardly any words, just lines, sketches and symbols. Doubtless, these meaningful scribbles would be true "sketch maps". One would have to draw to help one another, to get along, to move on. In addition, one would have to show the way to the others: the way through the city, or should we say, the way of life.

Marie Moreau used this technique during the ateliers, along with two other artists, Lauriane Houbey and Fabien Fischer. During the sessions, the artists would work with migrants, refugees and asylum seekers, comforting them on a moral level, while each individual would express themselves using oral language, body gesture, writing and/or drawing. Maps would begin to appear on various surfaces: on paper, cloth or even pieces of wood, some bi-dimensional, others tri-dimensional, such as Gladeema Nasrussin's clay map. As a child, in Sudan, he would create and sculpt with sand, so, naturally, he began to model his map with clay. He entitled his map The World is stopping Us. There is obviously something therapeutic not only in Nasrussin's map, but in all these maps, which convey a mixture of feelings, such as nostalgia, regret, anger or hope.

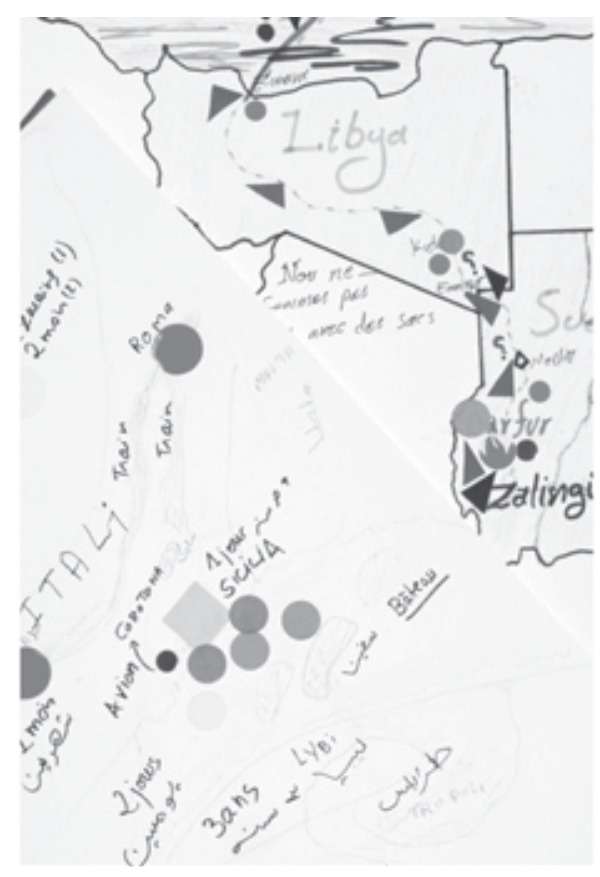

IMAGE 4. Cartographies traverses, research and creation project, creative ateliers involving asylum seekers, researchers and artists, 2013. 
Moreau has clarified the meaning of sticky labels she uses with migrants and which form a colourful key to the maps, translating constellations of words and feelings: red labels translate as danger, black as death, brown stickers point out luck and blue locate the police. In addition, one can choose the size of the label according to the intensity of the cold, how hungry one felt, or how strong a relationship was experienced. The migrants then use these labels on their maps, combining them with words and symbols.

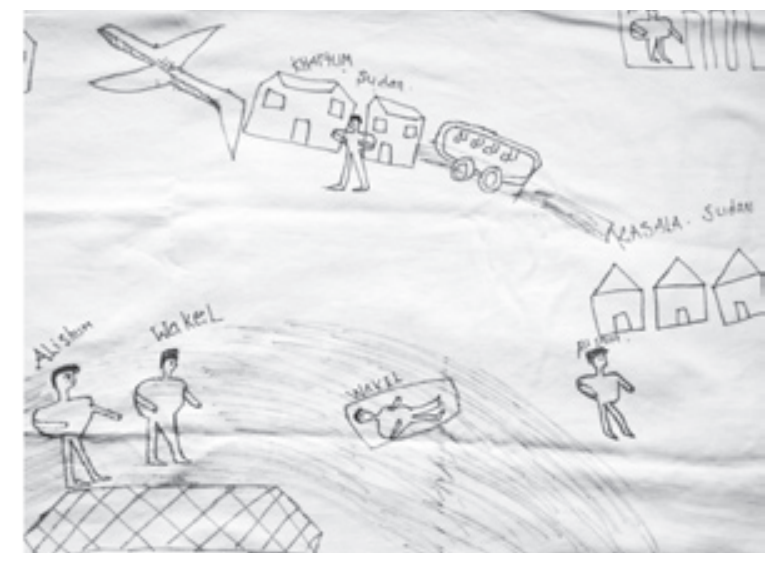

IMAGE 5. Cartographies traverses, research and creation project, creative ateliers involving asylum seekers, researchers and artists, 2013.

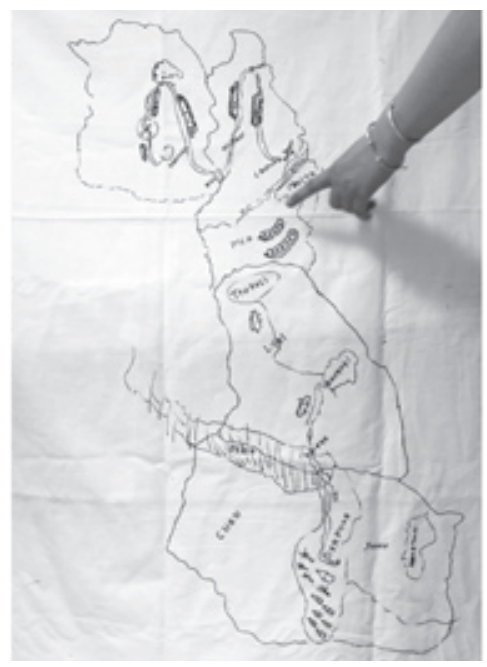

IMAGE 6. Cartographies traverses, research and creation project, creative ateliers involving asylum seekers, researchers and artists, 2013. 
Marie Moreau also suggests working on white cloth, which, she says, resembles the white shroud Muslims use to cover the deceased, for she believes it evokes friends and family who died during the journey. Working with cloth enables the use of either pens or embroidery, which, through the presence of the needle and thread, can also recall stitching a wound. Let us not forget that the migrants are still dealing with traumatic and painful memories. Some of the photographs documenting the sessions reveal how the hands relate to the white cloth, and how expressive they are, in such a way that the white material becomes symbolic to those who have fled their own country.

Whether the maps are drawn, sculpted or embroidered, they all show how the hands can become engaged in a healing process of traumatic loss, and how they can lead a displaced person along the way to adaptation in a new environment.

\section{Discussion}

These three significant works and their analyses hold important relevance beyond the scope of their immediate participants. All three pieces of artwork bear an underlying question which is the connection between maps and power. For instance, the upright hand in Boyer's work conveys ideas of identity and/or justice. Moreover, the collaborative work with Moreau could suggest subversive mapping or even activism. If we consider Karen O'Rourke's research into art and cartography, we could state that collaborative cartography can become a means of control. She notes that:

For the most part, the projects and tools of collaborative cartography draw connections among sources of information. This has not prevented cartographers from being accused of taking a superior, godlike view of whatever they are mapping. So do people map something to gain knowledge of it and ultimately power over it?

Thus, if we bear in mind this viewpoint, maps can be seen as truly empowering systems which can have both negative and positive sides to those

6 K. O'Rourke, Walking and Mapping, Artists as Cartographers, Cambridge: The MIT Press, Massachussetts, 2013, p. 207. 
who are part of the actual system itself. We may suggest that maps should be manipulated with precaution.

\section{Conclusion}

Our hands are linked to our 'path' of life. They tell our story. Céline Boyer's hands reveal how much the territory is embedded in us. Her geo-photographs begin to tell us how intertwined the hands, the map and the territory are. This is more evident in Khalili's installation work. The gesture of the hand opens up the space of the cartographic map, turning it into a "sketch map", bringing it to life. However, it is the Grenoble ateliers which reveal how the hand and the map can play a role in adapting to a new life, after the traumatic experience of a war, a dictatorship, extreme poverty or a precarious journey. The plasticity of the "sketch map" seems to soothe harrowing memories and the feeling of loss. The gesture involved in these participatory sessions is a form of communication, and, therefore, adaptation. Touch, gesture, traces show how much the human hand still has to say. It cannot be separated from the rest of the body and mind. The hand remembers, tells, plans and helps us make our way.

Taken together, all three artistic projects suggest a space for discussion and exchange.. These can be understood as important experiences for the participants in these projects. Each one of the participants in Boyer, Khalili and Moreau's projects voluntarily collaborated in diverse intersecting processes, which included storytelling, searching for comfort or guidance, and seeking or sharing advice. There are important links to be drawn between these artistic projects, the analysis presented in this paper, and the themes of memory, adaptation and migration. The importance of this work lies within sharing and remembering, travelling along paths of memory and transmitting knowledge, whether it is to simply bear witness of the terrible traumas of migration, or to find a form of relief or guidance; a way for adaptation to take place. 
Bridget Sheridan, Mapping the Way: The Use of Maps in Artistic Projects, Working with Migrants...

\section{References}

Focillon, H. (1934). Éloge de la main. In Vie des formes. Paris: Presses Universitaires de France

Ingold, T. (2016). Lines: A Brief History. Oxon, Routledge.

Jou, F. The Mapping Journey Project: la cartographie à l'état dynamique. In Textimage. http://www.revue-textimage.com/12_varia_5/jou1.html (accessed 18 August 2017).

Le Breton, D. (2003). La peau et les traces, Sur les blessures de soi. Paris: Editions Métailié.

O'Rourke, K. (2013). Walking and Mapping, Artists as Cartographers. Cambridge, MA: The MIT Press.

Tiberghien, G. A. (2007). Finis Terrae: Imaginaires et imaginations cartographiques. Paris: Bayard. 